\title{
Pengaruh Media Starter Dari Daging Nanas, BonggolNanas Dan KulitNanas Terhadap Kualitas Nata De Coco
}

\author{
Duma, Tri Harsono \\ Program Studi Pendidikan Biologi, Universitas Negeri Medan \\ romaduma360@gmailcom
}

\begin{abstract}
ABSTRAK
Penelitian ini bertujuan untuk Mengetahui Pengaruh Media Starter Dari Daging Nanas, Bonggol Nanas dan Kulit Nanas Terhadap Kualitas Nata De Coco. Metode yang digunakan dalam penelitian ini adalah Rancangan Acak Lengkap (RAL) dengan 3 faktor, 3 perlakuan dan 3 kali ulangan. Parameter yang diamati adalah ketebalan nata de coco, berat nata de coco dan uji organoleptik nya terhadap tektur dan warna nata de coco. Data yang diperoleh diolah menggunakan Rancangan Analisis Ragam (ANAVA) pada taraf 1\% dan 5\%, berpengaruh nyata atau tidak berpengaruh nyata. Hasil Penelitian menunjukkan bahwarata-rata ketebalan nata de coco dari media starter daging nanas sebesar $1,36 \mathrm{~cm}$, bonggol nanas sebesar $1,5 \mathrm{~cm}$, dan pada media starter dari kulit nanas sebesar 1,4 cm. Hasil rata-rata dari Berat nata de coco dari media starter daging nanas diperoleh 1.226gram, pada bonggol nanas diperoleh 1,350 gram, dan pada media starter dari kulit nanas diperoleh 1.325 gram.
\end{abstract}

Kata kunci : Tanaman nanas, nata de coco, media starter

\section{Starter Media Influence Of Meat Pineapple, Tuber PineappleAnd PineappleSkin On TheQuality OfNataDe Coco}

\begin{abstract}
This study aims to Know Starter Media Influence Of Meat Pineapple, tuber Pineapple and Pineapple Skin on the Quality of Nata De Coco. The method used in this study is completely randomized design (CRD) with 3 factors, 3 treatments and 3 replications. The parameters measured were the thickness of nata de coco, heavy nata de coco and its organoleptic test of the texture and color of nata de coco. The data obtained were processed using the Design Analysis Of Variance (ANOVA) at the level of $1 \%$ and 5\%, significant or not significant. Research shows that the average thickness of nata de coco from starter media pineapple flesh of $1.36 \mathrm{~cm}$, pineapple hump of $1.5 \mathrm{~cm}$, and the media starter of pineapple skin was $1.4 \mathrm{~cm}$. The average yield of Weight nata de coco from starter media pineapple flesh obtained 1,226 grams, the stump was obtained 1.350 grams pineapple, and the media starter of pineapple skin obtained 1,325 grams.
\end{abstract}

Keywords: pineapple plants, nata de coco, media starter

\section{Pendahuluan}

Tanaman nanas merupakan salah satu jenis tanaman buah yang dapat tumbuh baik di indonesia. Oleh karena itu, tanaman nanas dapat dijumpai hampir di seluruh indonesia. Sentra produksi nanas terutama ada di jawa barat, di jawa timur, sumatera selatan, jambi, riau, dan sulawesi selatan. Nanas tumbuh dengan baik di daerah yang memiliki curah hujan tinggi tetapi tidak tahan hidup pada lahan yang tergenang cukup lama (Samadi, 2014).
Sebuah nanas hanya 53\% bagian saja yang dapat dikonsumsi, sedangkan sisanya dibuang sebagai limbah, sehingga limbah nanas semakin lama semakin menumpuk dan umumnya hanya dibuang sebagai sampah (Rulianah 2002). Hal tersebut membuka peluang dalam pemanfaatan limbah nanas berupa kulit dan bonggol, menjadi produk yang Iebih bermanfaat. Salah satu alternatif yang dapat dilakukan adalah melalui fermentasi dengan bakteri Acetobacter xylinum menjadi produk natasebagai bahan makanan. Kandungan utama nata adalah selulosa 
bakterial yang memiliki kekhasan sifat struktural dan fisiko kimiawi dihasilkan dalam keadaan murni, seperti bebas lignin, hemi selulosa, dan produk biogenik lainnya (Yoshinagaet al,1997)

Makanan yang kaya akan serat salah satunya adalah nata. Nata merupakan makan pencuci mulut, yang mengandung serat mengandung selulosa kadar tinggi yang bermanfaat bagi kesehatan dalam membantu pencernaan. Nata adalah suatu bahan makanan hasil fermentasi oleh bakteri (Acetobakter xylinum) yang kaya akan selulosa bersifat kenyal, transparan dan rasanya menyerupai kolangkaling (Astuti, 2010).

Nata adalah sejenis makanan hasil fermentasi oleh bakteri Acetobacter xylinum, membentuk gel yang mengapung pada permukaan media atau tempat yang mengandung gula dan asam yang berbentuk padat, kokoh, kuat, putih, kenyal dan mirip kolang-kaling (Enggrid, 2012).

Nata merupakan selulosa sintetik yang dihasilkan oleh bakteri Acetobacter xylinum. Bakteri nata ini berasal dari biakan murni atau bibit. Biakan murni merupakan bakteri yang berada dalam kondisi dormansi (istirahat) dan belum terkontaminasi mikroorganisme lainnya. Awalnya, biakan murni perlu diaktifkan terlebih dahulu, yakni dengan menyedikan kondisi lingkungan (suhu dan $\mathrm{pH}$ ) yang optimal dan makanan yang dibutuhkan (Warisno, 2004).

Komponen yang cukup berperan sebagai media pertumbuhan nata adalah sumber karbon dan sumber nitrogen karena sebagai nutrisi bagi pertumbuhan bakteri Acetobacter xylinum. Sumber karbon sebagai salah satu unsur pembentuk nutrisi untuk medium fermentasi dapat berupa glukosa, fruktosa dan sukrosa. Media yang diperlukan untuk pembentuan nata antara lain : gula yang digunakan sebagai sumber karbon yang berperan penting dalam pertumbuhan mikroba. Bakteri Acetobacter xylinum mampu mensintesis nata dari glukosa, maltose maupun gliserol. Macam dan kadar gula yang ditambahkan akan mempengaruhi ketebalan dan sifat nata yang terbentuk. Sukrosa sering digunakan sebagai sumber karbon, karena merupakan gula lokal, harganya murah dan menghasilkan nata yang tebal dan keras. Kadar sukrosa $5-10 \%$ pada media fermentasi akan menghasilkan nata yang tebal dan keras (Enggrid, 2012).

Pada umumnya pembuatan nata menggunakan gula pasir sebagai tambahan makanan bakteri. Selain gula pasir dapat juga digunakan gula aren. Gula aren asli yang diambil secara tradisional lebih sehat dari pada gula tebu. Gula aren mengandung rasa dan aroma yang khas, karena dibuat dari didihan nira aren segar pilihan. Lebih lunak terhadap lambung atau pencernaan dan melancarkan metabolisme tubuh (Enggrid, 2012).

Pemanfaatan buah nanas sebagai bahan baku pembuatan nata de coco telah dilakukan, namun belum ada penelitian yang membuat media starter dari daging buah nanas, bonggol nanas dan kulit nanas terhadap kualitas nata de coco.

Dengan demikian penulis ingin meneliti tentang pemanfaatan buah nanas dalam pembuatan media starter. Dengan Judul: "Pengaruh Media Starter Dari Daging Nanas, Bonggol Nanas Dan Kulit Nanas Terhadap Kualitas Nata De Coco".

\section{Bahan dan Metode Lokasi dan Waktu Penelitian}

Penelitian ini dilakukan di Laboratorium Hamsa, Jl. M. Yakub Gg. Nangka No.5. Medan Perjuangan. Waktu penelitian dilaksanakan pada bulan Januari 2016 sampai bulan Februari 2016.

\section{Populasi dan Sampel}

Populasi dalam penelitian ini adalah Nanas (Ananas comosus (L) Merr). Sedangkan sampel yang digunakan dalam penelitian ini adalah Nanas. Sampel tersebut dikupas lalu dipisahkan daging, bonggol dan kulitnya kemudian air nya secara keseluruhan digunakan sebagai sampel untuk dijadikan media starter.

\section{Jenis Penelitian}

Penelitian ini bersifat eksperimental menggunakan Metode Rancangan Acak Lengkap (RAL). Dengan 3 faktor. Dari rancangan tersebut didapatkan 3 perlakuan dan setiap perlakuan dilakukan 3 kali ulangan.

\section{Prosedur Penelitian}

Penelitian ini diawali dengan tahap pembuatan Media Starter dari daging Nenas, Bonggol nenas, dan Kulit nenas. Dalam tahap ini, daging, bonggol, ataupun kulit nenas, diblender, lalu disaring pakai kain yang bersih., di ambil perasan airnya sebanyak 1 liter dan di rebus, tambahkan 30 gr gula pasir, 3 gr ammonium sulfat, ukur $\mathrm{pH}$ nya, setelah mendidih tuang pada botol yang bersih sebanyak $500 \mathrm{ml}$ perbotol kemudian ditutup, inokulasikan dengan Acetobacter xylinum $100 \mathrm{ml}$, lalu di fermentasikan selama 3 hari.

Kemudian tahap pembuatan nata de coco, dalam tahap ini air kelapa dibiarkan hingga kotorannya 
mengendap. Selanjutnya, saring menggunakan kain bersih dan panaskan 30 liter air kelapa di atas api yang besar hingga mendidih sambil terus diaduk. Lalu tambahkan gula sebanyak 900 gram, 60 gram Ammonium sulfat, dan $30 \mathrm{ml}$ asam asetat glasial. Lalu di ukur pHnya. setelah larutan mendidih di biarkan sampai 15 menit lalu dituangkan kedalam baki sebanyak 1,2 Liter, kemudian ditutup pakai kertas karton, setelah dingin di inokulasi dengan media starter dari daging nanas, bonggol nanas, dan kulit nanas sebanyak $120 \mathrm{ml}$ lalu kemudian di fermentasikan selama 7 hari.

Kemudian tahap Uji Organoleptis terhadap nata de coco, pada tahap ini nata dipotong-potong berbentuk kubus kemudian dicuci dalam air bersih lalu direbus, setelah mendidih nata ditiriskan dan direbus kembali sebanyak $3 \times$ perebusan. Setelah itu ditiriskan sampai air nya benar - benar kering dan ditambahkan gula sebanyak $1 / 3$ dari berat natanya.di biarkan selama 1 malam.

\section{Teknik Analisi Data}

Data yang diperoleh dari penelitian dianalisis dengan analisis ragam (ANAVA) untuk RAL. Pengolahan data dilakukan secara manual dengan bantuan Ms. Excel, sedangkan Uji Organoleptik terhadap tekstur, dan warna nata de coco dianalisis secara langsung.

\section{Hasil dan Pembahasan}

Dari hasil penelitian ketebalan nata de coco diperoleh hasil bahwa rata-rata jumlah perlakuan daging nanas yaitu $1,36 \mathrm{~cm}$, sedangkan pada bonggol nanas yaitu $1,5 \mathrm{~cm}$, sedangkan pada kulit nanas yaitu $1,4 \mathrm{~cm}$. dan Berdasarkan hasil uji statistik dengan menggunakan Rancangan Analisis Varians (ANAVA) dapat dilihat bahwa ada pengaruh nyata dari media starter daging nanas, bonggol nanas, dan kulit nanas terhadap kualitas nata de coco, dimana di Peroleh $F_{\text {hitung }}=8,8$ lebih besar dari $F_{\text {tabel }}(0,05)=5,14$ dan lebih besar dari $F_{\text {tabel }}(0,01)=6,66$. Hal ini menunjukkan bahwa $\mathrm{H}_{\mathrm{a}}$ di terima dan $\mathrm{H}_{0}$ di tolak.

Tabel 1. Data Hasil Pengukuran Ketebalan Nata De Coco

\begin{tabular}{|l|l|l|l|l|}
\hline \multirow{2}{*}{ Ulangan } & \multicolumn{2}{|l|}{ Perlakuan } & \multirow{2}{*}{ Total } \\
\cline { 2 - 4 } & Daging & Bonggol & Kulit & \\
\hline 1 & 1,4 & 1,5 & 1,4 & \\
\hline 2 & 1,4 & 1,5 & 1,4 & \\
\hline 3 & 1,3 & 1,5 & 1,4 & \\
\hline
\end{tabular}

\begin{tabular}{|l|l|l|l|l|}
\hline Total (Yi) & 4,1 & 4,5 & 4,2 & 12,8 \\
\hline Rata- rata & 1,36 & 1,5 & 1,4 & 4,26 \\
\hline
\end{tabular}

Dari hasil penelitian berat nata de coco didapatkan rata-rata jumlah perlakuan daging nanas yaitu 1.226 gram, sedangkan pada bonggol nanas yaitu 1.350 gram, sedangkan pada kulit nanas yaitu 1.325 gram, dan Berdasarkan hasil uji statistik dengan menggunakan analisis varians (ANAVA) pada tabel 4.4 dapat dilihat bahwa tidak ada beda nyata pengaruh dari media starter dari daging nanas, bonggol nanas, dan kulit nanas terhadap berat nata de coco, dimana di peroleh $\mathrm{F}_{\text {hitung }}=1,32$ lebih kecil dari $\mathrm{F}_{\text {tabel }}(0,05)=5,14$ dan lebih besar $F_{\text {tabel }}(0,01)=6,66$. Hal ini menunjukkan bahwa $\mathrm{H}_{0}$ di terima dan $\mathrm{H}_{\mathrm{a}}$ di tolak.

Tabel 2. Data Hasil Pengukuran Berat Nata De Coco

\begin{tabular}{|l|l|l|l|l|}
\hline \multirow{2}{*}{ Ulangan } & \multicolumn{2}{|l|}{ Perlakuan } & \multirow{2}{*}{ Total } \\
\cline { 2 - 4 } & Daging & $\begin{array}{l}\text { Bonggol } \\
\text { nanas }\end{array}$ & $\begin{array}{l}\text { Kulit } \\
\text { nanas }\end{array}$ & \\
\hline 1 & 1.325 & 1.350 & 1.325 & \\
\hline 2 & 1.325 & 1.350 & 1.325 & \multirow{2}{*}{} \\
\hline 3 & 1.030 & 1.350 & 1.325 & \\
\hline Total (Yi..) & 3.095 & 4.050 & 3.975 & $\begin{array}{l}11.70 \\
5\end{array}$ \\
\hline Rata- rata & 1.226 & 1.350 & 1.325 & 3.901 \\
\hline
\end{tabular}

Dari hasil uji Organoleptik 15 orang panelis diperoleh hasil rata-rata yang menyukai tekstur dari daging nanas, bonggol nanas, dan kulit nanas sama, tidak ada perbedaan yang nyata terhadap tektur nata. Rata- rata yang menyukai daging nanas sebesar 2 panelis, pada bonggol nanas 2 orang dan kulit nanas 2 orang. Berdasarkan hasil penelitian yang dilakukan didapatkan hasil bahwa tekstur nata pada daging nanas, teksturnya itu kenyal dan pada bonggol nanas juga tekstur yang didapatkan kenyal dan pada kulit nanas teksturnya kenyal, tidak ada perbedaan yang nyata dari tekstur nata, karena dipengaruhi oleh proses pembentukan selulosa oleh Acetobacter xylinum. Karena semakin lama waktu inkubasi maka akan menghasilakn selulosa yang semakin banyak pula dan tekstur nata yang kenyal, karena masih tersedianya niutrisi yang cukup sehingga bakteri secara terus menerus melakukan metabolisme.

Dari hasil uji Organoleptik 15 orang panelis diperoleh rata-rata yang menyukai warna dari daging nanas, bonggol nanas, dan kulit nanas 
sama, tidak ada perbedaan yang nyata terhadap warna nata. Rata- rata yang menyukai daging nanas sebesar 2 panelis, pada bonggol nanas 2 orang dan kulit nanas 2 orang, dan Berdasarkan hasil penelitian yang dilakukan didapatkan hasil bahwa warna nata pada daging nanas, warnanya itu putih dan pada bonggol nanas didapatkan putih dan pada kulit nanas warnanya putih, tidak ada perbedaan yang nyata pada warna nata.nilai tersebut menunjukkan bahwa warna nata de coco disukai para panelis karena bewarna putih layaknya warna nata pada umumnya. Hasil yang didapatkan ini menunjukkan bahwa tidak terjadi penyimpangan warna pada nata de coco, karena bahan nutrisi yang ditambahkan khususnya ammonium sulfat tidak lebih dan sumber karbon.

Berdasarkan hasil uji statistik pada ketebalan nata de coco dari pengamatan didapatkan bahwa ada pengaruh yang nyata pada media starter dari daging nanas, bonggol nanas, dan kulit nanas terhadap ketebalan nata de coco. Didapatkan hasil bahwa Ha di terima sedangkan Ho ditolak. Dengan menggunakan uji lanjutan uji BNT $5 \%$ dapat dilihat bahwa ketebalan nata yang tinggi terdapat pada bonggol nanas sedangkan pada daging dan kulit nanas memberikan nilai yang rendah.

Berdasarkan hasil uji statistik berat nata dari daging nanas, bonggol nanas dan kulit nanas, didapatkan bahwa hasil dari berat nata de coco tidak ada perbedaan yang nyata, yang berarti bahwa Ho di terima dan Ha ditolak. Hal ini disebabkan karena tidak ada perbedaan variasi dari masing masing perlakuan yang dilakukan, sehingga nutrisi bakteri Acetobacter xylinum cukup terpenuhi dari ketiga perlakuan

Berdasarkan hasil dari uji organoleptik dari perlakuan media starter dari daging nanas, bonggol nanas, dan kulit nanas, tidak ada interaksi antar perlakuan pada nilai tekstur nata de coco. Selain itu dapat diketahui bahwa tidak berbeda nyata. Rata- rata nilai tekstur dari perlakuan sama, tidak berbeda nyata. Tidak ada nilai tekstur yang paling tinggi didapatkan dari pengamatan yang dilakukan. Menurut Widya (1984), nata yang mempunyai struktur selulosa yang longgar maka nilai teksturnya akan tinggi (kekenyalannya menurun).

Nilai tekstur yang tinggi disebabkan oleh kepekatan medium fermentasi yang ada sehingga pembentukan selulosa oleh bakteri terjadi secara lambat yang pada akhirnya menghasilkan nata dengan susunan selulosa yang lebih longgar sehingga banyak air yang terperangkap didalamnya (kurniadewi, 2003).

Berdasarkan hasil dari uji organoleptik dari perlakuan media starter dari daging nanas, bonggol nanas, dan kulit nanas, tidak ada interaksi antar perlakuan pada nilai warna nata de coco. Selain itu dapat diketahui hasil bahwa tidak berbeda nyata. Rata- rata nilai warna dari perlakuan sama, tidak berbeda nyata. Tidak ada nilai warna yang paling tinggi didapatkan dari pengamatan yang dilakukan.

\section{Simpulan}

Berdasarkan hasil penelitian dan pembahasan dalam penelitian ini dapat diambil kesimpulan sebagai berikut: Kualitas nata de coco dengan menggunakan media starter dari daging nanas, memiliki rata-rata ketebalan nata pada daging nanas sebesar $1,36 \mathrm{~cm}$, pada berat nata de coco sebesar 1.226 gram, dan pada uji organoleptik pada tekstur nata kenyal dan warna nata de coco didapatkan putih bersih. Kualitas nata de coco dengan menggunakan media starter dari bonggol nanas, memiliki rata-rata ketebalan nata pada bonggol nanas sebesar $1,5 \mathrm{~cm}$, pada berat nata de coco sebesar 1.350 gram, dan pada uji organoleptik pada tekstur nata kenyal dan warna nata de coco didapatkan putih bersih. Kualitas nata de coco dengan menggunakan media starter dari kulit nanas, memiliki rata-rata ketebalan nata pada kulit nanas sebesar $1,4 \mathrm{~cm}$, pada berat nata de coco sebesar 1.325 gram, dan pada uji organoleptik pada tekstur nata kenyal dan warna nata de coco didapatkan putih bersih.

\section{Ucapan Terimakasih}

Terima kasih penulis ucapkan kepada Bapak Dr. Hasruddin , M.Pd selaku Ketua Jurusan Biologi yang telah memberikan izin kepada penulis untuk melakukan penelitian di Laboratorium Hamsa, Medan Perjuangan.

\section{Daftar Pustaka}

Astuti, P., 2010, Pengaruh Variasi Starter Antara Nira Kelapa, Dan Air Kelapa Terhadap Kualitas Nata De Coco, Skripsi, Fakultas Matematika Dan Ilmu Pengetahuan Alam (FMIPA) Universitas Sumatera Utara, Medan.

Badan Pusat Statistik Indonesia., 2009, Holtikultura Produksi Buah-Buahan Di Indonesia, Badan Pusat Satastik Republik Indonesia. 
Budiyanto., 2004, Mikrobiologi Terapan, Edisi Pertama, Cetakan Ketiga, UMM Press, Malang.

Darmansyah., 2010, Evaluasi Sifat Fisik Dan Sifat Mekanik Material Komposit Serat/Resin Berbahan Dasar Serat Nata De Coco Dengan Penambahan Nanofiller. Tesis Universitas Indonesia.

Dewi, A. S., 2011. Peningkatan produksi riboflavin bakteri Acetobacter xylinum pada starter nata de coco dengan penambahan minyak kelapa sawit, Skripsi, Fakultas Teknik Universitas Indonesia Departemen Teknik Kimia, Depok, 2011.

Enggrid, L., 2012, Pengaruh Jenis Gula Dan Lama Fermentasi Terhadap Kualitas Nata De Pina Dari Bahan Baku Buah Nanas, Skripsi, Fakultas Tarbiyah Dan Keguruan Universitas Islam Negeri Sultan Syarif Kasim Riau, Pekanbaru.

Hayati, M., 2003., Membuat nata de coco, Cetakan pertama, Adicita Karya Nusa.

Jusman, N., 2009, Kajian Pertumbuhan Bakteri Acetobacter Sp. Dalam Kombucha-Rosela Merah (Hibiscus Sabdariffa) Pada Kadar Gula Dan Lama Fermentasi Yang Berbeda, Tesis Universitas Sumatera Utara 